\title{
The Relationship between Post-Secondary Stress and Academic Motivation in the Children of Veterans of Mazandaran Province
}

\author{
Hamzeh. $M^{1}$ \\ Hojjati. $\mathrm{H}^{2}$ \\ *Akhondzadeh. $\mathrm{G}^{3}$ \\ 1- MSc in Nursing, Ali Abad Katoul \\ Branch, Islamic Azad University, \\ Ali Abad Katoul, Iran. \\ 2- Ph.D. in Nursing, Assistant \\ Professor, Nursing Department, \\ Ali Abad Katoul Branch, Islamic \\ Azad University, Ali Abad Katoul, \\ Iran. \\ 3- ( ${ }^{*}$ Corresponding Author) \\ Ph.D. in Nursing, Assistant \\ Professor, Nursing Department, \\ Ali Abad Katoul Branch, Islamic \\ Azad University, Ali Abad Katoul, \\ Iran. \\ Email: G_akhoondzadeh@ \\ yahoo.com
}

\begin{abstract}
Introduction: One of main challenges for people involved in war is post-traumatic stress disorder, associated with unpredictable or destructive and long-term consequences for the injured person, his family and the community. Post-traumatic stress disorder has been recognized as a stressful topic in the veterans' family; thus, it can affect children's academic motivation.
\end{abstract}

Objective: The present study examined the relationship between secondary posttraumatic stress disorder and academic motivation in veterans' children.

Material and Methods: This descriptive correlational study was performed on 150 children of veterans with secondary post-traumatic stress disorder in Mazandaran in 2018 with a simple random sampling. Data were collected using a Demographics Questionnaire, Post-traumatic Stress Disorder (STSS) and academic motivation scale. Data were analyzed using descriptive (Table, $\mathrm{M}$ ean and standard deviation (SD)) and inferential (t-pair, independent $t$ and ANCOVA) statistical tests at the significance level of $\mathrm{P}<0.01$. The material used for these analyses was SPSS 16

Results: The mean and standard deviation of post-traumatic stress and academic motivation in veterans' children were $43.97 \pm 13.9$ and $92.03 \pm 26.7$, respectively. Further, there was no significant relationship between post-traumatic stress disorder and academic achievement motivation $(\mathrm{P}=0.15)$.

Discussion and Conclusion: According to the results, post-traumatic stress disorder did not have a significant effect on the educational motivation of veterans' children. Therefore, it is recommended to teach ways to increase the motivation of academic achievement to deal with secondary post-traumatic stress disorder.

Keywords: Motivation, Post-Traumatic Education, Stress Disorders, Veterans. 


\section{ارتباط استر س آسيب ثانويه با انكيزش تحصيلى در فرزندان جانبازان استان مازندران}

مر تضى حمزه'، حميد حجتى"، "'كلبهار آخوندزاده

جـكيده

مقدمه: از مهمترين مشكلات براى افراد در كير با جنگ، ابتلا به اختلال استرس يس از سانحه است كه با بيامدهاى غيرقابل ييشبينى يا مخرب و بلند مدت براى فرد آسيبديده، خانواده وى و اجتماعى كه در آن زندگى مى كند همراه است. از آنجايى كه اختلال استرس پِ از سانحه به عنوان يك موضوع ير استرس در خانواده جانبازان شناخته شده است؛ بنابراين

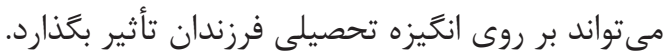

هدف: يزوهش حاضر به بررسى ارتباط استرس آسيب ثانويه با انغيزش تحصيلى در فرزندان جانبازان انجام شد.

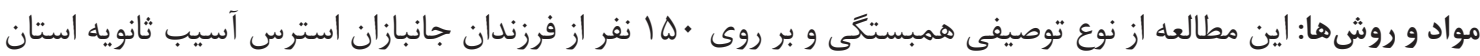

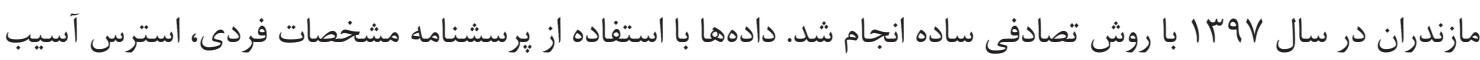

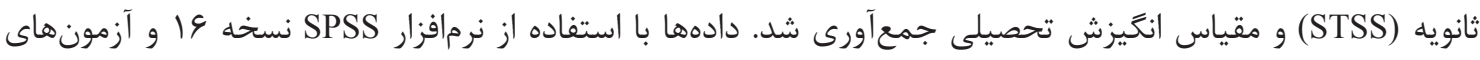

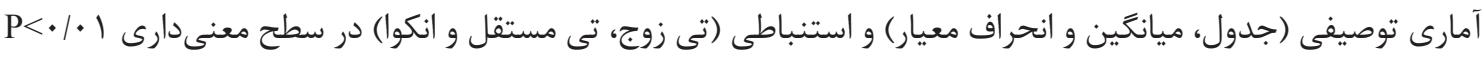
تجزيه تحليل شد.

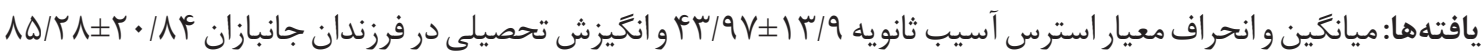
نشان داده بود، همجنين بين اختلال استرس يّ نيابتى با انكَيزه يِشرفت تحصيلى ارتباط معنىدارى وجود نداشت $(\mathrm{P}=\cdot / / Q)$ بحث و نتيجه كيرى: با توجه به نتايج به دست آمده، استرس آسيب ثانويه با انغَيزش تحصيلى فرزندان جانبازان ارتباط معنى دارى نداشته است. لذا، آموزش شيوههاى افزايش انخيزه يِيشرفت تحصيلى در جهت مقابله با استرس آسيب ثانويه توصيه مى

كلمات كليدى: اختلال استرس يس از سانحه، انخًيزه، تحصيل، جانباز.

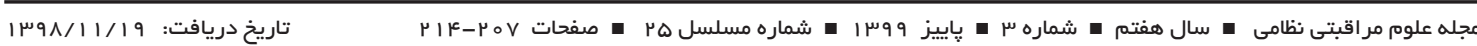
تاريخ يذيرش: ت تاريخ درياف:

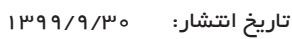

استرس ״ֶ از سانحه است (Y). اختلال استرس ״ֶ از سانحه

سندرمى است كه (PTSD: Post-Traumatic Stress Disorder) يس از مشاهده، شنيدن يا در گَير شدن با يك عامل استرسزاى

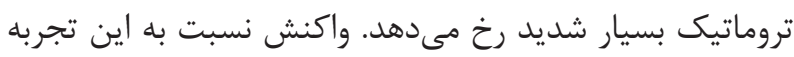

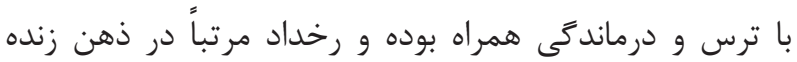
مىشود و فرد سعى مى كند از يادآور شدن آن اجتناب كند (بّ).
جنگ ييامدهاى اقتصادى- اجتماعى، فرهنكى و روانشناختى

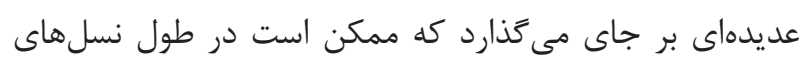
متمادى تأثير جشمخيرى بر روابط اعضاى جامعه باقى كذاردارد.

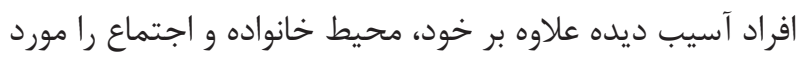
مخاطره قرار مىدهند (1). يكى از عوارض مههم جنگ اختلال 
افسردگى و عدم اعتماد به نفس، كناه و خشم غير قابل كنترل

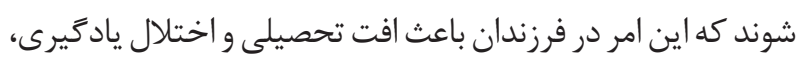

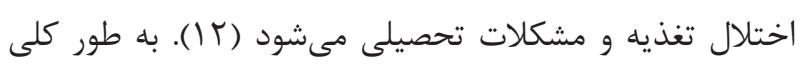

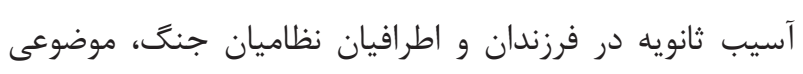

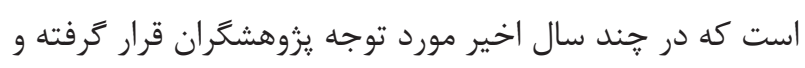

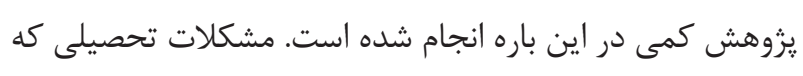

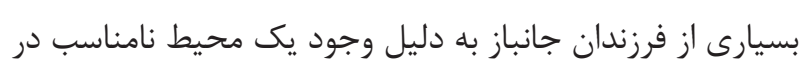

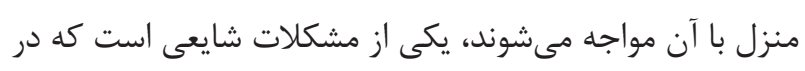

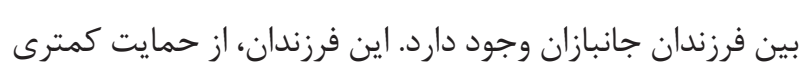
از سوى خانوادههاى خود برخوردارند و خانوادههاى ايشان، دخالت

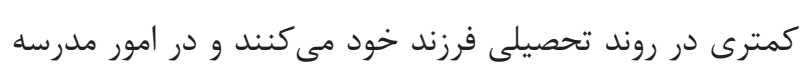

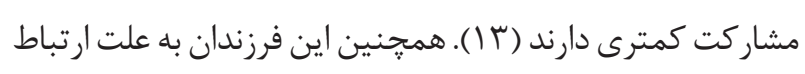
نامناسبى كه از كودكى ممكن است با ٍِدر داشته باشند و مشكلات

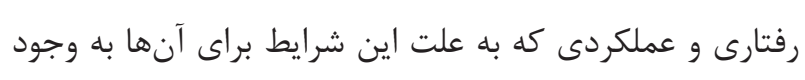

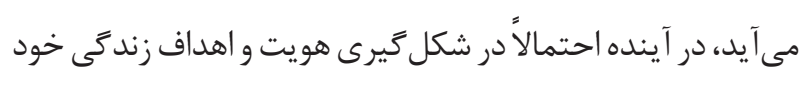
دجار مشكل مى شوند و اهداف تحصيلى نيز مانند ساير ابعاد زندكى لئى

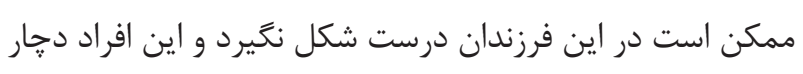
يكى هويت سر كردان در طول تحصيل خود شوند همين مسئله

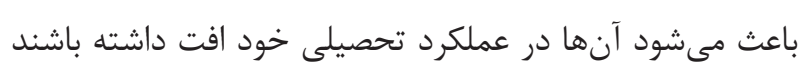

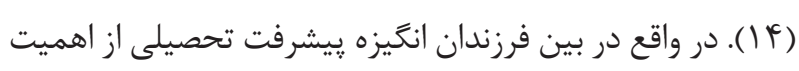

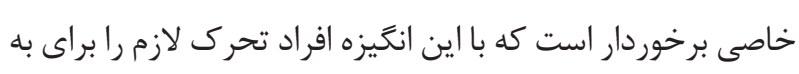

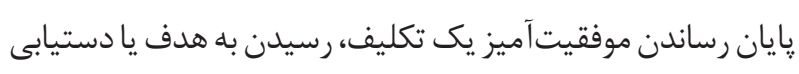
به درجه معينى از شايستكى در كار خود دنبال مي كنند تا بالاخره بتوانند موفقيت لازم را در تحصيل كسب نمايند (ها (ا)؛ بنابراين

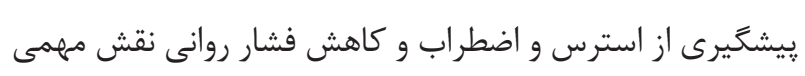

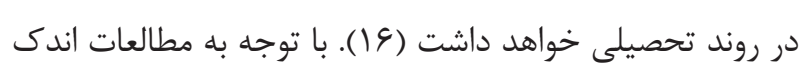

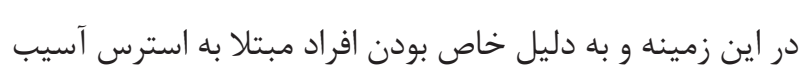
ثانويه لزوم بررسى هاى بيشتر در اين زمينه احساس مى شودو. لذا،

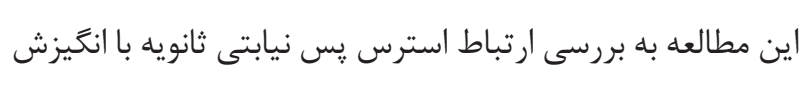
تحصيلى در فرزندان جانبازان انجام شد.

\section{مواد و روشها} اين يزوهش يك مطالعه توصيفى تحليلى از نوع همبستخى مى باشد رون
اختلال استرس يس از سانحه (PTSD) مى تواند در واكنش به

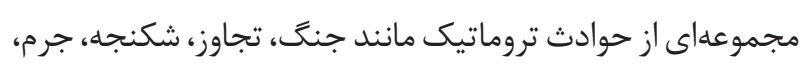

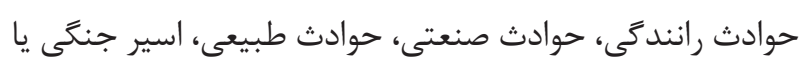

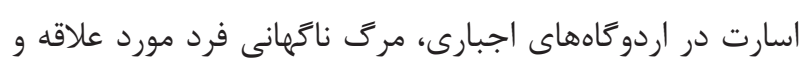

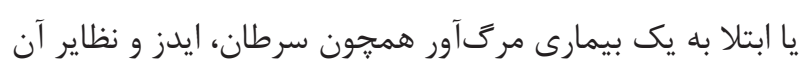

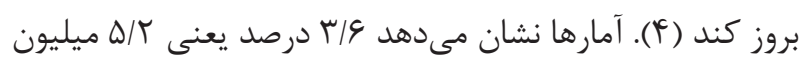

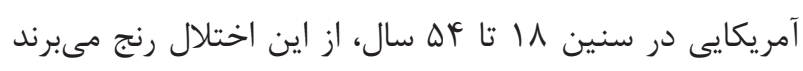

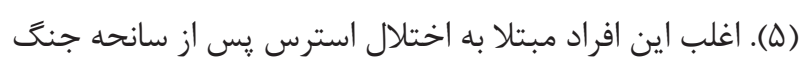

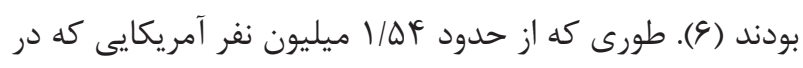

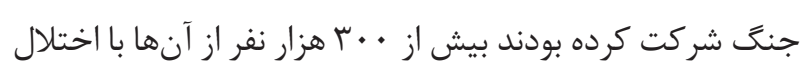
استرس يس از سانحه جنكى به خانه بركشته بودند (V) (V). در ايران

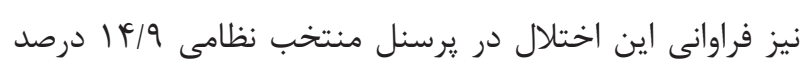

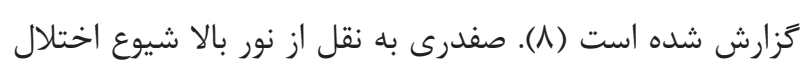

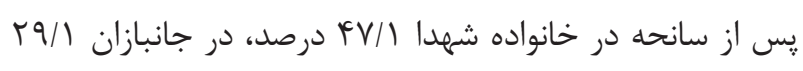

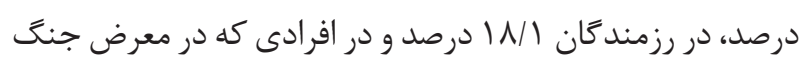

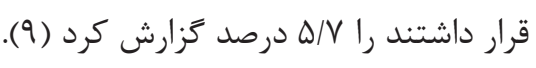

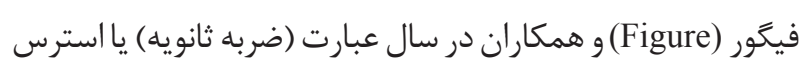

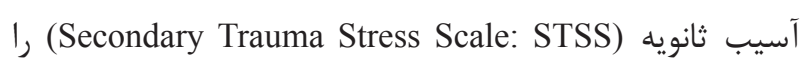
جهت توضيح اين و يديده مطرح نمودهاند. همه افرادى كه دركنار قربانيان ضربه شديد زندگى مى كنند خودشان مى توانند قربانيان

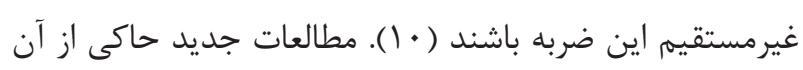

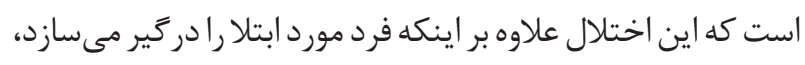

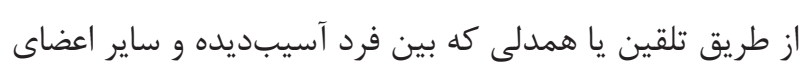

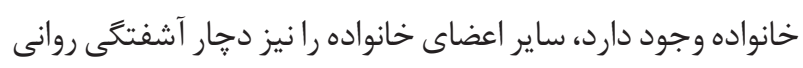
مى كند كه اين يديده را اختلال استرس يس از سانحانه (PTSD)

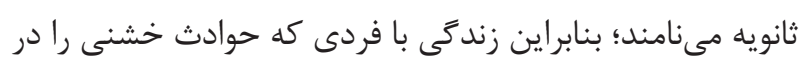
زندگى تجربه كرده است، ممكن است ساير افراد خانواده را نيز در زندگى تحت تأثير قرار دهد. علائم PTSD يا ساير واكنشها

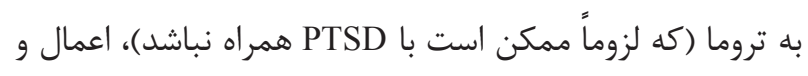

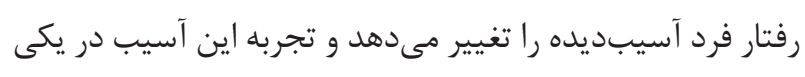

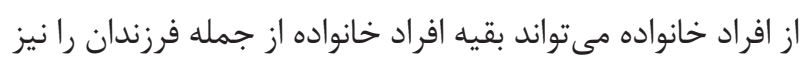

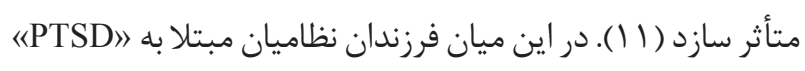
به طور دائم در معرض مستقيم خشم، افسردگى، احساس كناه

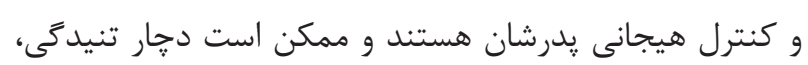


ضريب آلفاى كرونباخ نمره كلى آن در همسران جانبازان 9 ـ •

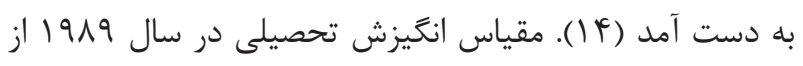

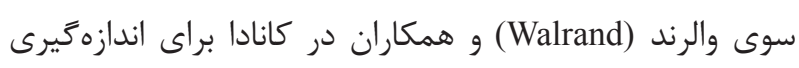

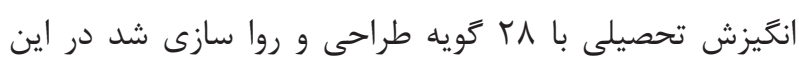

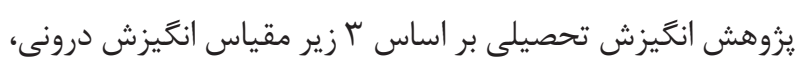

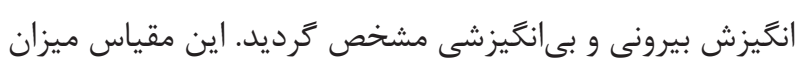

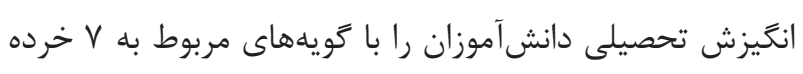
مقياس (انًَيزه درونى براى فهميدن، انخَيزه درونى براى انجام كار،

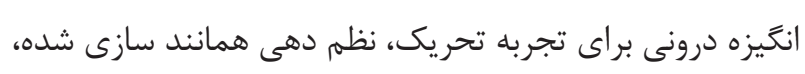

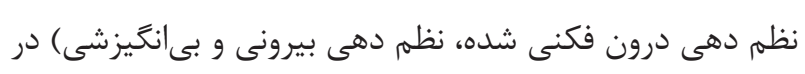

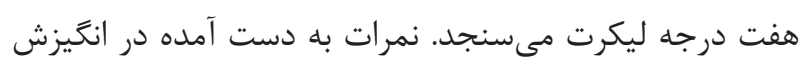

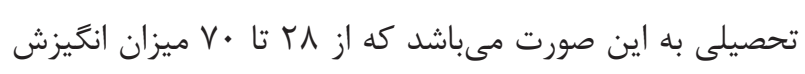

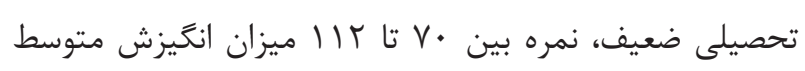

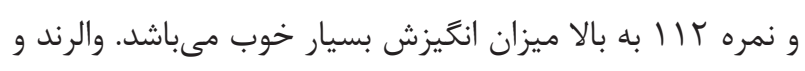

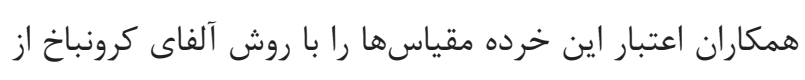

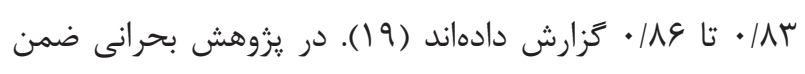

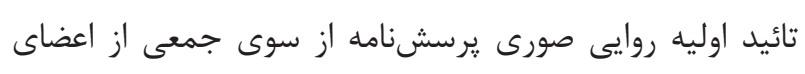

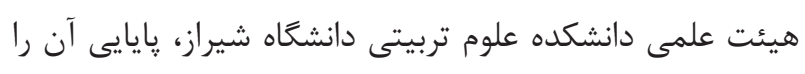

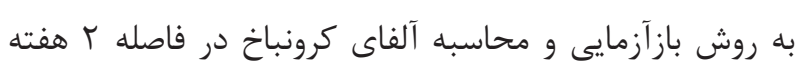

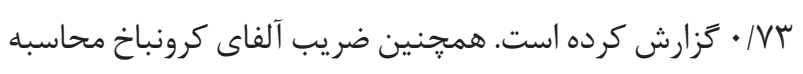

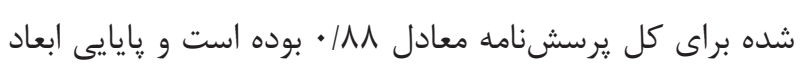

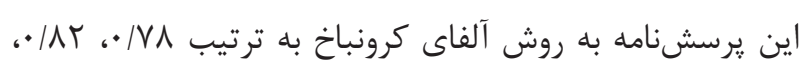

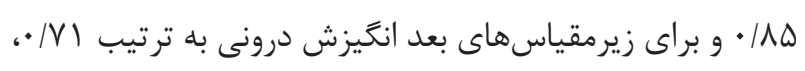

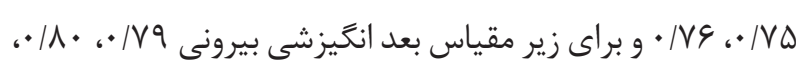

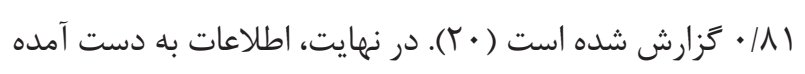

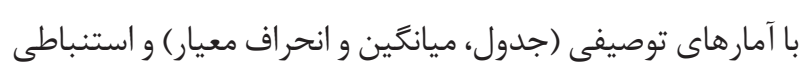

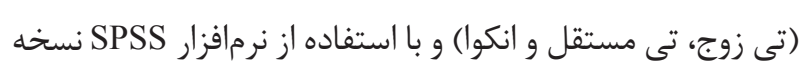
19 مورد تجزيه و تحليل قرار كرفت.

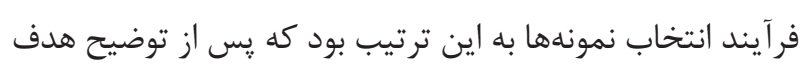

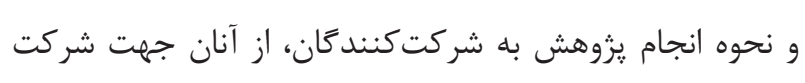
در يزوهش دعوت به عمل آمد و در صورت موافقت، فرم رضايت

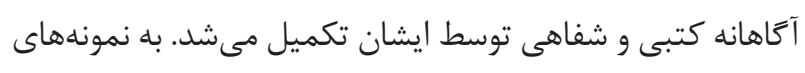

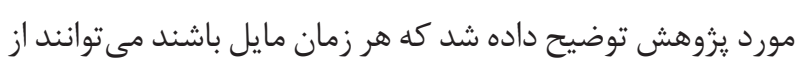

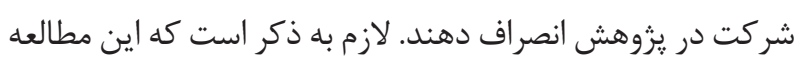

مازندران در سال Y Y I انجام شد. نمونهها با روش تصادفى ساده

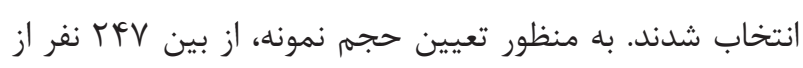

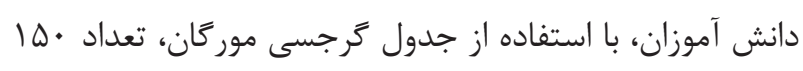

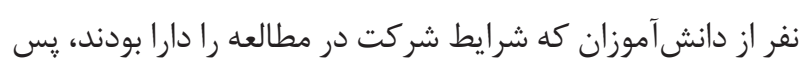

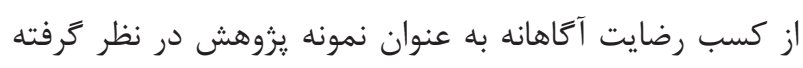

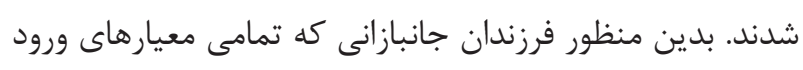

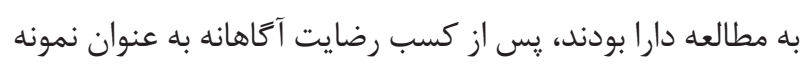
يزوهش در نظر كرفته شدند. معيارهاى ورود شامل: دانشآموز و و

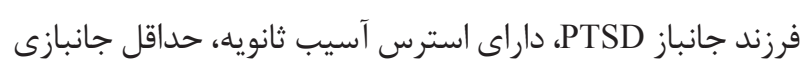
يدر ها درصد و كسانى كه والدينشان با يكديخر زندكى مى كنيند.

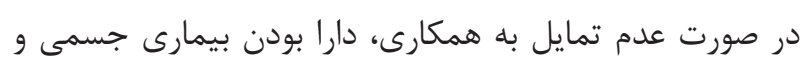

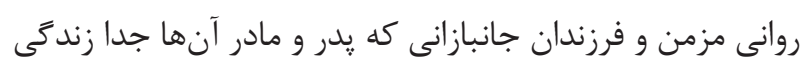
مى كنند از مطالعه حذف شند ورند. ابزار تردآورى دادهها در اين يزوهش شامل: مشخدئ مشنصات فردى، استرس آسيب ثانويه (Secondary Trauma Stress Scale: STSS)

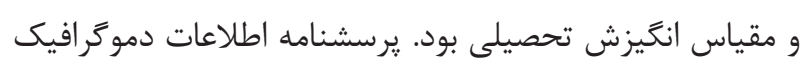
شامل: جنس، سن، سطح تحصيلات فرزندان، تحصيلات والدين،

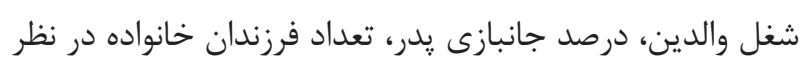

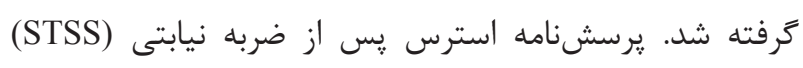

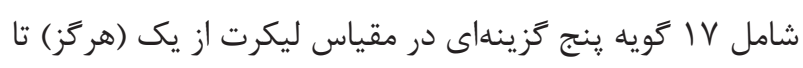

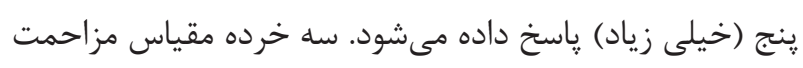

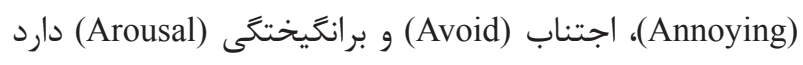

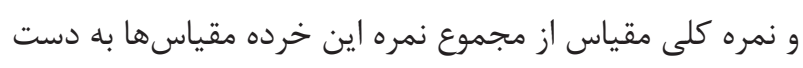

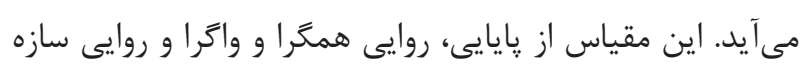

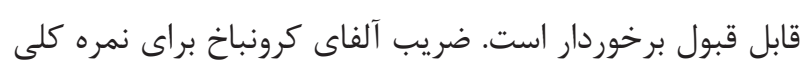

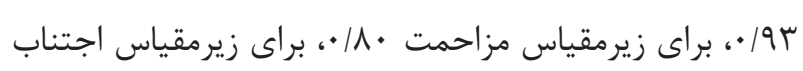

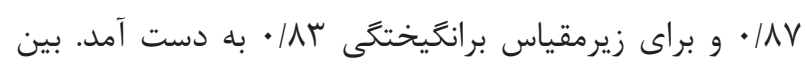

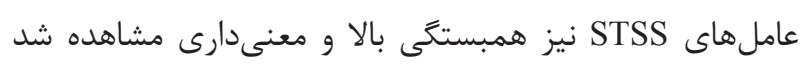
(IV) (IV)

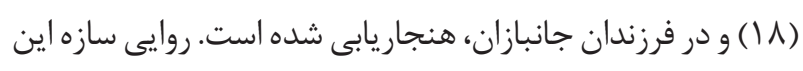
مقياس در هر دو يزوهش با استفاده از تحليل عاملى مورد تائيد قرار

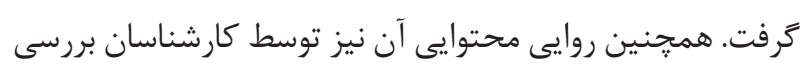

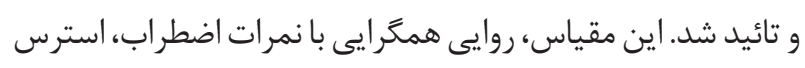

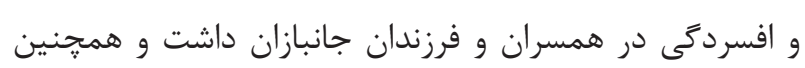


جدول ا- مشخصات جمعيت شناختى فرزندان جانبازان استان مازندران در

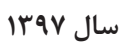

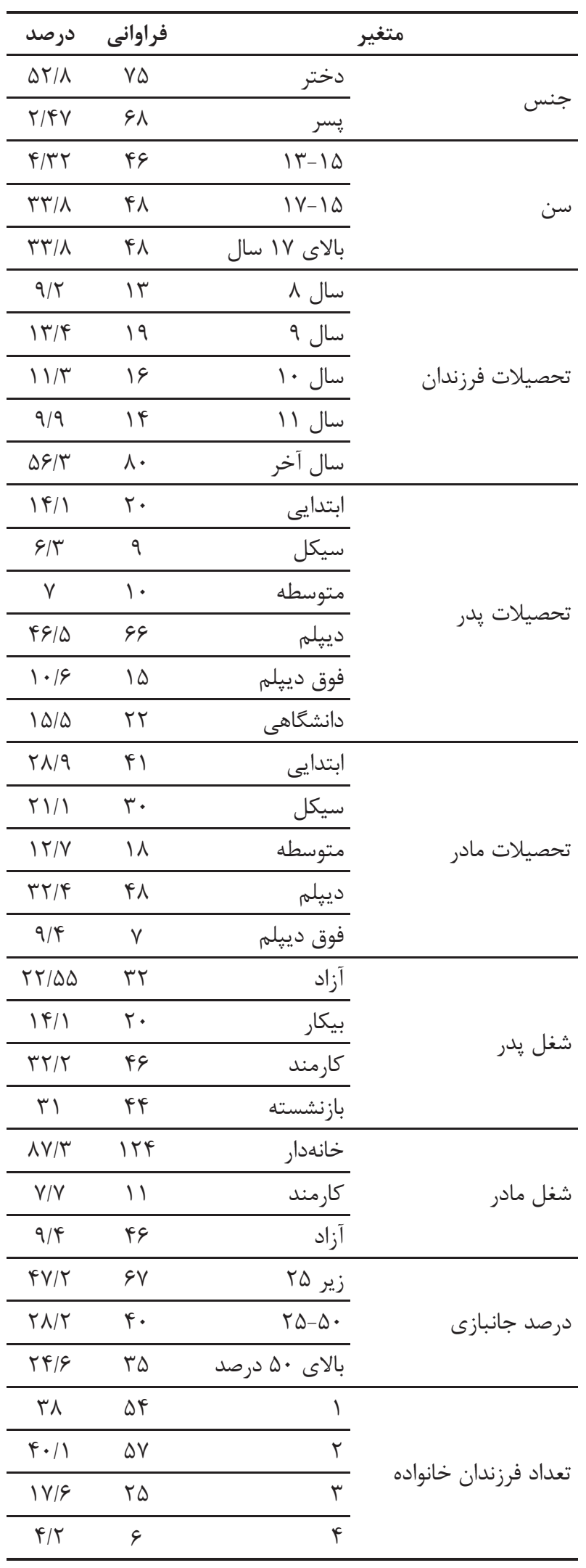

بركَرفته از پايان نامه كارشناسى ارشد مىباشد كه با شناسه اخلاق

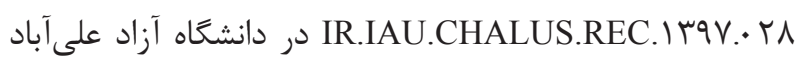
كتول تصويب ترديده است.

\section{يافته ها}

يزوهش حاضر بر روى • له ا نفر از فرزندان جانبازان مورد بررسى قرار كرفت. در مقايسه مشخصات جمعيتشناختى از كل افراد

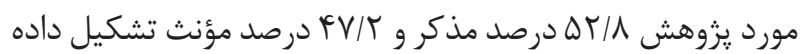

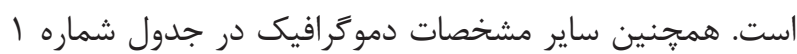

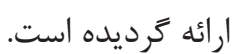
نتايج اين مطالعه ميزان استرس آسيب ثانويه رادر فرزندان جاندان جانبازان

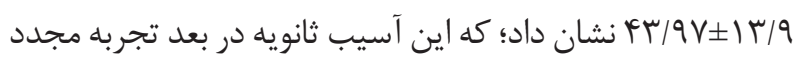
حادثه آسيب زا

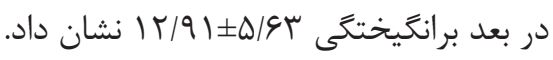

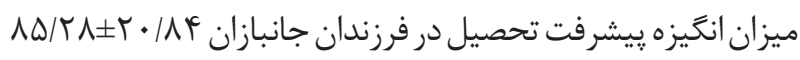

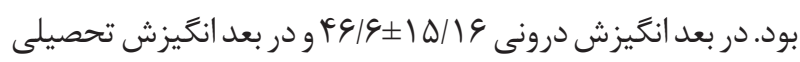

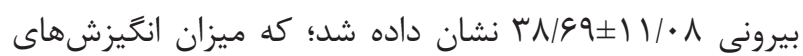
درونى بيشتر از بيرونى بوده است.

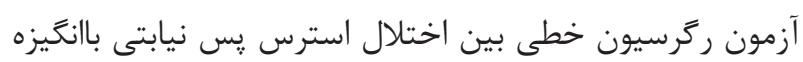

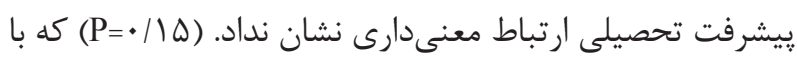

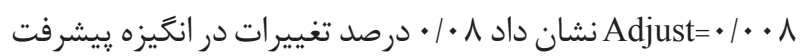

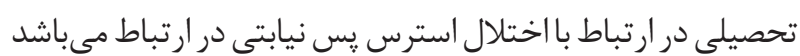

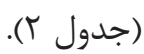

\section{بحث و نتيجهديرى}

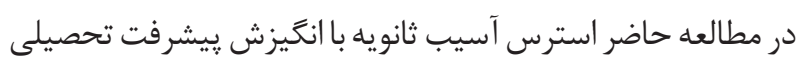

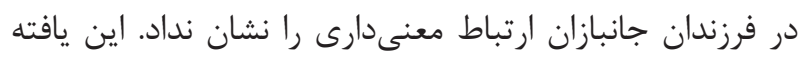

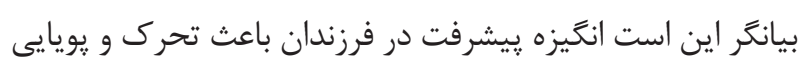

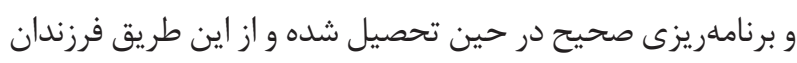

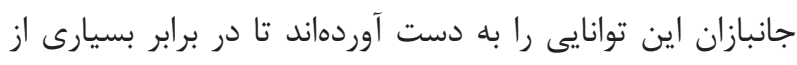

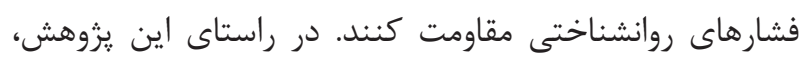

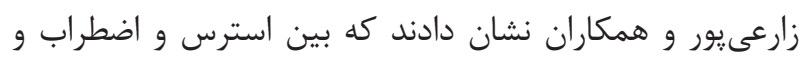

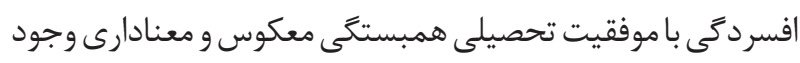

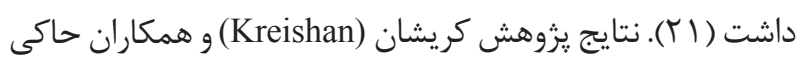




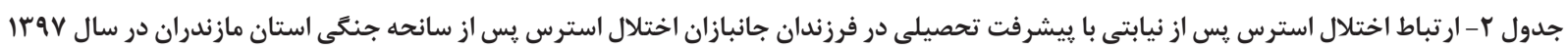

\begin{tabular}{|c|c|c|}
\hline سطح معنى دارى & ميانغين و انحراف معيار & متغير \\
\hline $\mathrm{P}=\cdot / 10$ & $F r / q V \pm I r / q$ & اختلال استرس يس نيابتى \\
\hline beta $=. / 1 r \quad B=\cdot / r r$ & $\Lambda \Delta / r \Lambda \pm r \cdot \mid \Lambda r$ & انخيزه يِيشرفت تحصيلى \\
\hline
\end{tabular}

روان، انگيزش ييشرفت تحصيلى و عملكرد تحصيلى دانشجويان بر اساس شاخصهاى برازش الگو تائيد شد و همجنين رفتارها نشان داد كه سلامت روان بر انگيزش پيشرفت تحصيلى و انگيزش بران ييشرفت تحصيلى بر عملكرد تحصيلى مؤثر بوده است (•r) كه

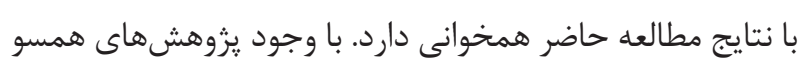
با يافتههاى يزوهش حاضر، يزوهشى يافت نشد كه با يافتههاى يزوهش حاضر ناهمخوان باشد. در تبيين نتايج حاصل از اين مطالعه مىتوان كَت مديريت انخيزش به افراد كمك مى كند تا درك بهترى از اهداف و شيوههاى مناسب دستيابى به آن ها داشته باشند و بتوانند جهت انتخاب و دنبال كنند. محدوديتهاى اين يزوهش عبارت بود از عدم تمايل به همكارى بعضى از فرزندان براى شركت در يروهش

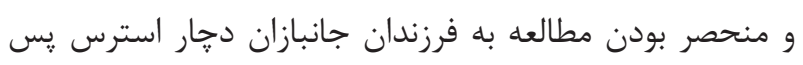
نيابتى ثانويه استان مازندران كه قابل تعميم به فرزندان جانباز استانهاى ديخر نيست. با توجه به محدوديتهاى ياد شده در بالا، از لحاظ يثوهشى ״يشنهاد مىشود كه در تحقيقات آتى از حجم نمونه بزرگتر در استان هاى ديخر هم استفاده كردد. همجنين يِيشنهاد مى شود كه در تحقيقات آتى مداخلات آموزشى رابراى فرزندان و خانواده جانبازان دجار استرس ڤس از سانحه به طور جدى در سياست گذارىهاى بهداشتى مد نظر قرار زيرد. با توجه به نتايج مطالعه مىتوان كفت، انگيزه تحصيلى باعث

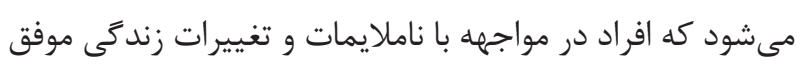
شوند. آنها قادر به اداره كردن و شناختن محيط براى غلبه بر فشارهاى زندگى و برآورده كردن ضروريات آن مىشوند. آنها قادر به ساز گارى سريع و شناخت وضعيت، فهم روشن وقايع، برقرارى ارتباط و عمل انعطافيذير مىشوند؛ بنابراين اين مطالعه بينش كرانبهايى را در زمينه انخيزه تحصيلى فرزندان جانبازان نشان داد كه مىتواند براى مسئولين حائز اهميت باشد.
از آن بود كه بين جهت گيرىهاو انخًيزش درونى و بيرونى با موفقيت تحصيلى هيج ارتباط معنادارى وجود ندارد (Y Y). شمس الدينى لرى و همكاران در يزوهش خود مبنى بر بررسى تأثير استرس بر انخيزه ״يشرفت تحصيلى در بين دانشجويان دختر و پِر دانشعاه يِيام نور نشان دادند كه بين پيشرفت تحصيلى و استرس دانشجويان دختر رابطه معنادارى وجود ندارد (TM) كه با نتايج مطالعه حاضر همسو است. در مقابل نتايج مطالعات كاراتاس (Karatas) و همكاران نشان داد بين انخَيزه درونى با موفقيت تحصيلى ارتباط مثبت معنادارى وجود دارد (YY). يافتههاى حسنزاده و مهدىنزاد گرجى نشان دادند كه بين انخيزش درونى و مؤلفههاى آن با ريشرفت تحصيلى دانشآموزان در درس زبان انگليسى همبستخى مثبت و معنادارى

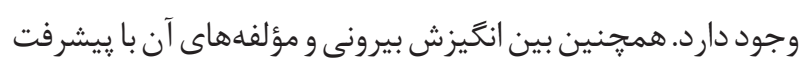
تحصيلى دانشآموزان در درس زبان انعليسى رابطهى مثبت بسيار

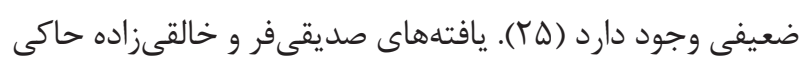
از آن بود كه جهت گيرى درونى انخيزش با برخوردارى از انخيزش درونى مى تواند ضامن يادگيرى و موفقيت تحصيلى دانشآموزان باشد (Y)). نتايج يافتههاى سعدىيور و همكاران نشان دادند كه بين اضطراب و انغَيزش بيشرفت تحصيلى رابطه معنادارى وجود

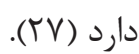

حميده و همكاران استرس و افسردگى را در عدم موفقيت معرفى مى كنند و به نظر مىرسد در دانشجويان يزشكى و سالهاى آخر تحصيل استرس بيشتر و افسردگى شايعتر بوده و اين اختلال سلامتى منجر به مشكلاتى در عدم موفقيت تحصيلى مى

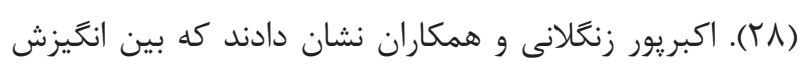
״يشرفت تحصيلى با سلامت روان ارتباط مثبت و معنىدارى وجود دارد (Y૧). نتايج : يزوهش ميركمالى و همكاران نشان داد كه سلامت روان با انخيزش پيشرفت تحصيلى، انگيزش يِيشرفت با عملكرد تحصيلى و همجنين افسردگى با عملكرد تحصيلى رابطه معنى دارى داشتهاند. در اين مطالعه، معادلات ساختارى سلامت 


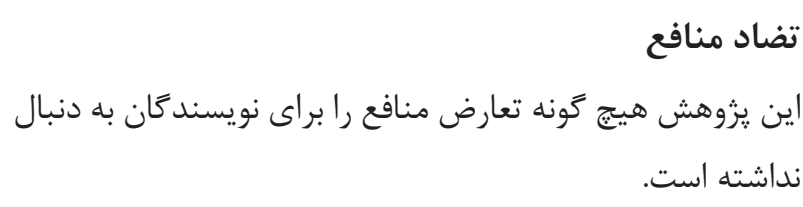

References

1- Zamani S, Veisani Y, Mohamadian F, Kikhavani S. The Prevalence of Posttraumatic Stress Disorder (PTSD) in People who Experienced Imposed War by Iraq on Iran in Ilam in 2016: CrossSectional Study. J Military Med. 2018;20(4):412-20.

2- Andersson P. Post-traumatic stress symptoms linked to hidden Holocaust trauma among adult Finnish evacuees separated from their parents as children in World War II, 1939-1945: a casecontrol study. International psychogeriatrics. 2011;23(4):61-654. DOI: 10.1017/S1041610210001791 PMID: 20849674

3- Ebrahimpour M, Azzizadeh Forouzi M, Tirgari B. The relationship between post-traumatic stress symptoms and professional quality of life in psychiatric nurses. Hayat, Journal of School of Nursing and Midwifery, Tehran University of Medical Sciences. 2016;22(4):312-24.

4- Noohi S, Miraghaie A, Arabi A. The Effetiveness of neurofeedback on anxiety, depression, and war post traumatic strees disorder symptoms. J Res behav sci. 2016;14(2):195-203.

5- Callahan D. Combat-related mental health disorders: the case for resiliency in the long war. J Am Osteopath Assoc. 2010;110(9):7520. PMID: 20876837

6- Zhou JN, Zhong Y, Ginsberg J, Singh N, Zhang J. Dysregulation in microRNA expression is associated with alterations in immune functions in combat veterans with posttraumatic stress disorder. PLoS One. 2014;9(4):75-94. DOI: 10.1371/journal.pone.0094075 PMID: 24759737

7- Bravo-Mehmedbasić AK, Kulenović A, Suljić E. Impact of chronic Posttraumatic Stress Disorder on the Quality of life of war survivors. Psychiatr Danub. 2010;22(3):5-403. PMID: 20856187

8- Sirati nir M, Ebadi A, Fallahi Khoshknab M, Tavallaie A. Consequences of living with Posttraumatic Stress Disorder:A Qualitative Study. Journal of qualitative Research in Health Sciences. 2012;1(2):92-101.

9- Safdari RA, Tofighi S, Karimi G. Comparactive survey of cilincal information managment system of war-related mental diseases. Payavard. 2009;3(1-2):57-64.

10- Rezapour Mirsaleh Y. The Relationship between Attachment Styles and Father-Child Conflict in Warfare victims chilren: Investigate the role of secondary trauma as a Mediator. Journal of Counseling research. 2017;15(57):81-100.

11- Mehrinejad A, Mokarrami M, Ostovar Z. Effect of Stress Management Training with Cognitive-Behavioral Therapy on Marital Adjustment in the Wives of War Veterans Suffering from Post-Traumatic Stress Disorder. The Neuroscience Journal of Shefaye Khatam. 2015;3(3):71-80. DOI: 10.18869/acadpub. shefa.3.3.71

12- Ebadi MA, Shafighi S. Post-traumatic Stress Disorder (PTSD). Journal of Army Nursing Faculty of the IRIran. 2012;12(2):68-77.

13- Habibzadeh AM, Lajovardi H. The Sense of Coherence and Education Self- Concept in Children of Veterans with Secondary Trauma Stress Disorder and Normal Children. J Military Med. 2016;17(4):283-90.

14- Rezapour Mirsaleh Y, Behjat Manesh A, Tavallaei S. Role of Secondary Post-Traumatic Stress Disorder and Resilience on Academic Motivation and Performance of Veterans' Student Children. Iranian Journal of War and Public Health. 2016;8(4):22533.

15- Reeve J. Understanding motivation and emotion: John Wiley \& Sons; 2014.

16- Antonovsky A. Unraveling the Mystery of Health. How People Manage Stress and Stay Well. San Fran-cisco: Jossey-Bass; 1987.

17- Bride B, Robinson M, Yegidis B, Figley C. Development and validation of the secondary trau-matic stress scale. Res Soc Work Pract. 2004;14(1):27-35. DOI: 10.1177/1049731503254106

18- Ahmadi K, Rezapour Y, Davoudi F, Saberi M. Investigate of validity and reliability of secondary trauma stress scale for evaluation of ptsd symptoms in samples of warfare victims' wives. Iran J War Public Health. 2013;5(3):47-57.

19- Vallerand R, Pelletier L, Blais M, Briere N, Senecal C, Vallieres E. The Academic Motivation Scale: A Measure of Intrinsic, Extrinsic, and Amotivation in Education. Educational and Psychological Measurement. 2016;52(4):1003-17. DOI: 10.1177/0013164492052004025

20- Bohrani M. Study academic Motivation of secondary students in the Fars Province and its correlated factors. J Social Sci \& Humanities of Shiraz Univ. 2005:22-45.

21- Zareipour M, Zareipour G, Alinejad M, Moharrami F, Abdolkarimi M. The Study of Stress, Anxiety, Depression and its Relationship with Educational Success in Teens in Salmas City Iranian J Pediat Nurs. 2019;5(3):37-42.

22- Kreishan L, Al-Dhaimat Y. Intrinsic and Extrinsic Motivation, Orientation and Achievements in L2 of Arab Learners of English, French and German: A Study from Jordan. International Education Studies. 2013;6(12). DOI: 10.5539/ies.v6n12p52

23- Lori S, Arabi Jongqaei V, Arabi Jongqaei A. Stress Study on Motivation for Academic Achievement among Male and Female Students of Payam Noorabar University in 2015-2015. Second 
National Conference on Sustainable Development in Educational and Psychological Sciences, Social and Cultural Studies; Tehran: Soroush Hekmat Mortazavi Islamic Studies and Research Center, Mehr Arvand Institute of Higher Education, Sustainable Development Solutions Center; 2015.

24- Karatas H, Alci B, Yurtseven N, Yüksel H. Prediction of ELT Students' Academic (Language) Achievement: Language Learning Orientation and Autonomous Learning. International Online J Educat Sci. 2015;7(1):10.15345/iojes.2015.01.014. DOI: 10.15345/iojes.2015.01.014

25- Hassanzadeh R, Mahdinejad Gorji G. The relationships between motivational orientation(intrinsicmotivation, extrinsic motivation $\&$ amotivation) anstudents' academic achievement in the english language. J School Psychology. 2014;3(3):136-43.

26- SediqiFar Z, Khalegheizadeh S. Motivational orientations and academic achievement of Persian language learners Farsi to non-Farsi language education research paper. Research paper for teaching Persian to non-Persian speakers. 2016;5(2):79-93.
27- SaadiPour E, ShojaeiPour M. The Relationship Between Anxiety, Academic Self-Esteem, and Students' Academic Achievement Motivation Payam Noor University of Bojnourd. J Educational Research. 2014;9(34):79-94.

28- Hamaideh S, Hamdan-Mansour A. Psychological, cognitive, and personal variables that predict college academic achievement among health sciences students. Nurse Education Today. 2014;34(5):703-8. DOI: 10.1016/j.nedt.2013.09.010

29- Akbarpoor Zanghalani M, Khodayari Shouti S, Malekzadeh A. The Relationship between Mental Health and Achievement Motivation among the Students of Tabriz University of Medical Sciences. Journal of Development Strategies in Medical Education 2016;2(3):14-24.

30- Mirkamali S, Khobare K, Mazari E, FarhadiAmjad F. TheRole of Mental Health andAcademicPerformance, Mediated by Achievement Motivation, Knowledge and Research. Journalof AppliedPsychology. 2015;16(60):39-54. 